Research Article

Received Date: $23 / 05 / 2020$

doi.org/10.46291/wwsj.v5i5.29
Accepted Date: 09/07/2020

\title{
Vajinusmus ve Migrenli Vakada Akupunktur Tedavisi
}

\author{
Hayriye Alp \\ Necmettin Erbakan Üniversitesi, GETAT Merkezi, Konya, hayriyebalp@yahoo.com
}

Orcid: 0000-0002-7262-2234

\section{Özet}

Giriş: Migren ve vajinusmus kadınlarda sık rastlanan durumlardır. Migren tipi baş ağrısı, binlerce yıldan beri bilinen bir hastalık olup, remisyon atak şeklinde klinik seyir izler. Primer başağrıları içerisinde yer almaktadır. Genel insidansı \%1-3 civarındadır. Vajinusmus bayan cinsiyette perine kaslarının istem dış1 kasılması sonucu ilişkiyi engelleyebilir ve ya rahatsılık verebilir. Her iki hastalık da stres kaygı düzeyi ile şiddeti doğru orantılı olarak artmaktadır.

Olgu: 37 yaşında bayan hemşire hasta menstrüasyon boyunca migren, vertigo, obezite, topuk dikeni, vajinusmus, cinsel isteksizlik şikayetleri ile başvurdu. Başvuru sırasında VAS 8 idi.D vit 23.76ng/dl, B12;317, TSH; 3,18 mU/L, İnsülin;32,1 idi. BMI; 25.9, hasta 68,9kg, $163 \mathrm{~cm}$ boyunda idi. TA 100/60mmhg, $\mathrm{Mg} ; 1,8$.

Metod: Hastaya 12 seans akupunktur uyguland1.DU-20,21, ST-24,25, LU-9,H-7,PC-6, UB-62, SP-6,9 Kulakta uterus, sıfır, shen-men, Hunger,topuk, jerome,göz, servikal noktaları alındı. Tek kullanımlık akupunktur iğneleri $(0.25 \times 25 \mathrm{~mm}$ ve $0.20 \times 13 \mathrm{~mm})$ kullanıldı. Hastaya $\mathrm{d}$ vit ve mag replasmanı verildi. Tiramin içeren gidalar kısıtlandı. Seanslar 20dk sürdü.

Sonuç: 2.seansta vertigo azaldı, Vas 2-3 e düştü.4. seansta topuk dikeni ağrısı yoktu.8.seansta hamile kaldı. Hasta sağlıklı bir gebelik süreci atlattı.

Tartışma: vajinusmus stres,korku ve gerginlik oluşturabilmektedir.Psikolojik semptomlar için akupunkturdan yararlanabilmektedir.Akupunktur endojen endorfin seviyesini yükselterek kayg1 stres düzeyini azaltmaktadır. IVF yapılan kadınlarda ET sırasında uygulanan akupunkturun klinik gebelik hızının devam eden gebeliğin ve canlı doğumu artırdığı tespit edilmiştir.

Anahtar Kelimeler: Migren, Vajinusmus, Akupunktur

\begin{abstract}
Absract
Migraine and vaginusmus are common conditions in women. Migraine-type headache is a disease known for thousands of years, it usually progresses with attacks, and what is known about migraine has been increasing recently.37-year-old female nurse presented with migraine, vertigo, obesity, heel spur, vaginusmus, sexual unwillingness during menstruation. At the time of application, VAS was 8.D vit 23.76ng / dl, B12; 317, TSH; 3.18, Insulin was 32.1. BMI; The patient was 25.9, the patient was $68.9 \mathrm{~kg}$ and $163 \mathrm{~cm}$ tall. TA 100/60, Mg; 1.8 patients underwent 12 sessions of acupuncture. DU-20,21, ST-24,25, LU-9, H-7, PC-6, UB-62, SP-6,9 Ear uterus, zero, shen- men, Hunger, heel, jerome, eye, cervical points were taken. Disposable acupuncture needles $(0.25 \times 25 \mathrm{~mm}$ and $0.20 \times 13 \mathrm{~mm})$ were used. The patient was given $d$ vit and mag replacement. Foods containing tyramine were restricted. The sessions lasted 20
\end{abstract}


minutes. In the second session, vertigo decreased, Vas decreased to 2-3. He did not have heel spur pain during the session. The patient survived a healthy pregnancy period.

Key words; Migraine, Vaginismus, Acupuncture.

\section{Giriş}

Akupunktur noktaları vücudumuz üzerinde bulunmaktadır.Bu noktalar basınç, 1şık,ses dalgası veya iğne ile uyarılabilirTürkiye' de en çok analjezik amaçla kullanılmaktadır. Akupunktur sadece semptomları ortadan kaldıran bir disiplin değil aynı zamanda hastalıkları tedavi edebilmektedir. Özellikli noktalar uyarılınca santral sinir sistemine stimulus gider, endorfinler salınır(20-200 çeşit). İnsandan elde edilen endorfinlerin morfinden 50 kat daha güçlü analjezik olduğu tespit edilmiştir. Endorfinler ağrının merkeze geçişini önlerler. Hastalık ve hastalığın ortaya çıkış zamanı ile endorfinlerin arasında bir ilişki vardır. Ağrının azaltılmasında bu endorfinlerin yapım ve yıkım hızı arasındaki denge önemlidir. Non-muskuloskeletal hastalıklarda ise endorfinden ziyade organ enerji dengelenmesi söz konusudur. Enerjinin bir kanaldan diğer kanala akışının sağlanması tıkanıklıkların giderilmesi vücudun kendi kendine tamirine olanak sağlar.

Günümüz modern tıpta vücudumuz birbirinden ayrı birimler şeklinde değerlendirilmektedir. Bu yaklaşımla beden bir arada tutulmamış onu parçalara ayırmış oluruz. Uzmanlık eğitimleri ile uzman hekimler bedenin sadece kendi uzmanlık alanlarıyla ilgili kısımları ile ilgilenirler. Akupunktur ise insan vücudunu hem enerji hem yapısal olarak ortak tedavi eder.İç organlarla dıştaki duyu organları arasında bağlantılar kurar.

Akupunkturun etkilerini şu şekilde sıralayabilir:

1. Analjezik etki

2. Homeostatik etki

3. İmmüniteyi artırıcı etki

4. Sedatif etki

5. Psikolojik etki

6. Motor iyileştirici etki 


\section{Analjezik Etki}

Akupunkturun ağrıyı gidermesi ile ilgili birkaç teori mevcuttur. Önce ağrı kavramı üzerinde açıklama yapmak gerekir. Ağrı, doku harabiyetinin eşlik ettiği hoşa gitmeyen emosyonel bir durum olarak tanımlanmaktadır. Emosyonel bozukluk limbik sistemdeki anormal aktiviteden doğmaktadır. Ağrı ilk 3 ay süreli akut, 3 aydan daha uzun süreli devam eden ağrı ise kronik ağrı olarak nitelendirilmektedir. Akut ağrı fizyolojik boyutu olup vücut için koruyucu nitelikte iken kronik ağrı koruyucu özellikleri bulunmamaktadır. Kronik ağrı nöropatik, visseral veya mixt tip olabilmektedir (Çevik C. 2016).

Akupunkturun ağrı giderme mekanizması başlıca 3 teori ile açıklanmaktadır:

1.Gate-kontrol(kap1 kontrol) teorisi

2. Nosiseptif Afferent Teorisi

\section{Endorfin Teorisi}

Gate kontrol Teorisinde ağrı olarak yorumlanan sinir impuls iletimleri fonksiyonel bir kapı ile kapatılarak önlenir. Spinal kordun dorsal boynuzundaki nöral mekanizmalar bir kapı gibi davranarak periferal liflerden gelen impulsların santral sinir sistemine akışı bu kapılarla düzenlenir. Periferal inputlar kapının etkisi ile santral sinir sistemine iletilir. Kapı aynı zamanda beyinden gelen impulsların da aşağı iletilmesini etkiler. Spinal kordun substantia jelatinozada bulunan internöronlar ağrı duyusunun iletimi üzerinde düzenleyici etkisi vardır. Düzenleyici etki dorsal boynuzdaki satral iletici hücrelerin aktive edilmesinden önce başlar (Mense S 1993, Dray A 1994) Küçük myelinsiz C lifleri aktivitesi ile kapı açık tutularak santral iletici hücreler santral mekanizmaları çalıştırır. A lifleri ise inhibitör etkilidir ve kapıyı kapalı tutarlar. Böylece santral iletici hücreler aktive olamaz. Santral iletici hücrelerin en son boşalımı büyük ve küçük liflerin rölatif aktivitelerine bağlıdır. Bu aktivitelerinin hangisi baskın ise kapı açılır veya kapanır. Melzack bu kavramı daha da ileriye götürerek herhangi bir periferik uyarı olmaksızın dorsal boynuzdan kortexe kadar uzanan iletim yollarındaki bazı anormal aktivitelerin ağrı oluşturabileceğini iddia etmiştir.(Çevik C.2016) 


\section{Nosiseptif Afferent Sistem Teorisi}

Ağrı duyusu reseptörlerle alınır, ilgili omurilik segmentinin dorsal kolonundan girer, medulla spinalis içerisinde anterolateral kısımda ilerler, lateral spinotalamik traktus ile talamusa oradan da serebral kortex duyu alanına gider. Ağrı normal bir duyu olarak kabul edilmez sadece patolojik hallerde duyulur. Bu sırada nosiseptif denilen ağrı reseptörleri aktive olur. Nosiseptörler aşırı mekanik, sıcak, soğuk ve kimyasal etkiler sonucu oluşan doku tahribatı ile uyarılırlar. Böylece vücudun kendini koruma mekanizmalarını devreye sokarlar. Ağrı duyusunun kendine özgü bir alıcı sistemi mevcuttur ve bu sistemuyarı yokken aktif değildir. Nosiseptörlerden doğan aşırı stimuluslar nosiseptif afferent sistemi ile cortexe gelir. Nosiseptif resptör sistemi birbirinden kesintisiz devam eden plexuslardan oluşur. Plexuslar mylinsiz sinir lifleri içerir ve bütün kan damarlarını çevreler. Normalde inaktif olan plexus sistemi doku gerilmeleri, laktik asit artışı, K+ yükselmesi, pH'nın 6'nın altına düşmesi, 5-hidroxitriptamin, polipeptid kininler, serotonin, histamin, prostaglandinler gibi kimyasallların ortaya çıkması ile aktive olurlar. Afferent sistem boyunca da kortexe iletilirler.(Çevik C. 2016) Substans P (SP) ve taşikininlerin lokal salınımı vazodilatasyon ve plazma ekstravazasyonuna yeter miktarda ise ödem meydana gelmesine sebep olur.( Schouenborg J 1986) P maddesi mast hücrelerinden histamin salg1latır.( Sorkin L 1993, Wang SM, 2001)

Dokularda ayrıca nosiseptif reseptörlere ek olarak mekonoreseptörler bulunur. Bu resptörlerden kalkan uyarılar da kalın ve ince liflerle taşınır. Kalın lifler mekanoresptör lifleri, ince lifler nosiseptör afferent lifleridir. İnce liflerin kalınlığı 5mikrometreden az olup somatik visseral olarak dorsal boynuzdan içeri girerler. Girişte spinal bazal nukleusta sinaps yaparlar. Sinirin bu nukleustaki aktivitesi anterolateral lifler ile merkeze çıkar, temporal lobda duyu olarak hissedilir. Önce periferal nosiseptif irritasyonla bazal spinal nukleuslar depolarize olur ve sonra uyarı beyne gönderilir. Aksi halde ağrı duyulmaz. Ağrının beyne ulaşıp ulaşmaması ile ilgili 2 mekanizma vardır: biri mekanoreseptör afferentleridir. ( apikal spinal nukleusla sinaps yapar, çapı 5-20 um arasındadır) Snapstan çıkan internöron bazal spinal nukleusta nosiseptif afferent axonu ile sinaps yapar.

Mekanoreseptörler aracılığıyla alınan bilgi inhibisyon yapan impulstur ve nosiseptif afferent impulsunun beyne götürülmesini inhibe eder. Benzer durum fizyoterapide kullanılan doku vibrasyonu, elektriksel uyarı, akupressör mekanoresptörlerin uyarılarak nosiseptif afferent liflerin 
inhibe edilmesi ile açıklanabilir. Bu sistemde mekanoreseptörlerin afferentleri inhibitör etkilidir.( Cervero F. 1994) Nosiseptif afferent uyarının beyne ulaştırılmasında supresif etki eder. Eğer mekanoresptör aktivitesi yüksek tutulursa ağrı kortexe ulaşmaz. Akupunktur işte bu mekanoresptör afferent aktiviteyi artırarak ağrıyı kesiyor olabilir. Akupunkturun beyne gönderdiği impulslar fonksiyonel manyetik rezonans çalışmaları ile gösterilebilmektedir. Sağlıklı gönüllülerle akupunktur yapılan hastaların fonksiyonel manyetik rezonans görüntüleri farklıdır.( UvnasMoberg K.1998, Cho SY 2013)

\section{Endorfin Teorisi}

Anterolateral spinal tractlar dahil olmak üzere liflerin \%30’u talamusun posterior çekirdeklerinden geçer fakat talamusla sinaps yapmaz. Uzantılar talamustan kortexe kadar ulaşır, ağrı talamusta değil kortexe ulaşan bu liflerin uyarılması ile oluşur. Talamustan kortexe uzanan lifler 3 bölgeye dağılır: bunlar paryetal, temporal, ve frontal loblardır.Talamus üzerinden paryetal bölgeye ulaşan impulslar ağrı hissi oluşturur. Oluşan ağrının vücutta hangi dokuda olduğu ve ağrının kalitatif yapısı bilgisi de belirlenir. (yakıcı, baskılayıcı, zonklayıcı, bıçak saplanır tarzda) bu sistemle acı algılanmaz; acı frontal loba gelen liflerin orbital ve cingulate kısımlarına ulaşması ile oluşur. Limbik sistemin aktive olması emosyonel nahoşluğu oluşturur. Limbik sistemdeki acı duyusu talamik sinapslar aracılığıyla nosiseptif afferent impulslardan gelir. Temporal bölgede hafiza yer alır; bu sistemin aktivitesi ile kişinin geçmişteki ağrı deneyimleri kodlanır. Örneğin ' hastanın ağrım var' şikayeti talomofrontal bağlantı sonucu, ağrının lokalizasyonu talamokortikal uzantılar(paryetal, insular, sentral) sonucu, ağrının ne zamandır olduğu ise temporal lob uzantıları kullanılarak cevaplanır. Ancak beynin bu üç bölgesi de retiküler formasyon aracılığıyla ilişkide olması nedeniyle ağrı duyulur, yeri tayin edilir ve hafızaya depolanır. Eğer uyarı düşük şiddette ise ağrı duyulur kabaca lokalize edilebilir fakat hafızaya alınmaz aradan geçen zamanla unutulur.(Çevik 2016)

Kulaktaki Shen men noktasının sedasyon yapıcı etkisi vardır ve uyarılması ile kortex fonksiyonları düzenlenir.(WANG Sm 2001) Vücutta liv-3 noktasının uyarılması da sedasyon etkisi yaratır. Kronik obstrüktif akciğer hastalığı olanlarda yapılan bir çalışmada hastaların dispne ve 6 dakika yürüme mesafesi, yaşam kalitesi önemli faydalar sağlamıştır. 
Retiküler nöronların uyarılabilirliği çeşitli faktörlerden etkilenir. Aynı periferik mekanoresptörler gibi görevleri mevcuttur. Bu sistemden çıkan aksonlar spinal apikal nukleus ve internöronlarla sinaps yaparak inhibisyona neden olabilirler. Bu inhibisyonda periaquaductal gri maddeden salınan BOS'a verilen endorfinler de rol oynamaktadır. Endorfinler retiküler sistem aktivitesini artırarak inhibisyonu sağlarlar. Akupunktur uygulanmasından hemen sonra hastanın endorfin seviyelerinde artış gözlenmektedir. Ayrıca retiküler nöronlar kaudal inhibitör kaskadların kaynağıdırlar.

Migren ve vajinusmus kadınlarda sık rastlanan durumlardır. Migren tipi baş ağrısı, binlerce yıldan beri bilinen bir hastalıktır. Primer başağrıları içerisinde yer almaktadır. Yapılan çalışmalar insidansını \%1-3 civarında olduğunu göstermektedir. Vajinusmus perineal kaslar kasılarak ilişkiyi zorlaştırmaktadır. Her iki hastalık da stres kaygı düzeyi ile şiddeti doğru orantılı olarak artmaktadir.

Olgu

37 yaşında bayan hemşire hasta menstrüasyon boyunca migren, vertigo, obezite, topuk dikeni, vajinusmus, cinsel isteksizlik şikayetleri ile başvurdu. Başvuru sırasında VAS 8 idi.D vit 23.76ng/dl, B12;317, TSH; 3,18, İnsülin;32,1 idi. BMI; 25.9, hasta 68,9kg, $163 \mathrm{~cm}$ boyunda idi. TA 100/60, Mg; 1,8 .

Metod

Hastaya 12 seans akupunktur uyguland1.DU-20,21, ST-24,25, LU-9,H-7,PC-6, UB-62, SP-6,9 Kulakta uterus, sıfır, shen-men, Hunger,topuk, jerome,göz, servikal noktaları alındı. Tek kullanımlık akupunktur iğneleri $(0.25 \times 25 \mathrm{~mm}$ ve $0.20 \times 13 \mathrm{~mm})$ kullanıldı. Hastaya d vit ve mag replasmanı verildi.Tiramin içeren gıdalar kısıtlandı. Seanslar 20dk sürdü. Sonuç

2.seansta vertigo azaldı, Vas 2-3 e düştü.4. seansta topuk dikeni ağrısı yoktu.8.seansta hamile kald1. Hasta sağlıklı bir gebelik süreci atlatt. Tartışma

İlişkiye girmede psikolojik semptomlar yaşanmaktadır.. Akupunktur endojen endorfin seviyesini yükselterek kaygı stres düzeyini azaltmaktadır. IVF yapılan kadınlarda ET sırasında uygulanan akupunkturun klinik gebelik hızının devam eden gebeliğin ve canlı doğumu artırdığı tespit edilmiştir. Yapılan bir metaanaliz çalışmasında tüm akupunktur çeşitleri değerlendirilmiş ve 
akupunktur ile tedavi alan invitro fertilizasyon tedavisinde klinik gebelik oranlarını kontrol grubuna göre daha yüksek olduğu bulunmuştur. Özellikle kontrollü over hiperstimülasyonu sırasında oldukça başarılı bulunmuştur(Qian 2017).

Migren hastalarında $\mathrm{Mg}$ gibi bazı mineral düşüklüğü ve exprese edilen genler de ağrı şiddetini artırabilmektedir(Bao,2014).Migren hastalarının ağrısında tedavi ederken göz önünde bulundurulmalıdır. Bizim vakamızda da Mg düzeyi düşük idi.

Akupunkturun gerek anksiyeteyi azaltması ,gerekse hormonal denge ile obeziteyi azaltması ve uterus kan akımını düzenlemesi ile bu tür hastalıkların tedavisinde yardımcı olabilir. Akupunktur semptomların geriletilmesinde etkilidir. Yapılan prokotol oluşturrma çalışmalarında farklı semptomlarda zorunlu noktalara; depresyonda HT7; LI3/SP6/HT5 uygulanmış sham lazer akupunktur klinik çalışmalarda başarılı bir şekilde uygulanmış ve plaseboya üstünlüğü gösterilmiştir(Kramer 2017).

\section{Kaynaklar}

Çevik Cemal, Medikal Akupunktur. Kuban matbaacılık yayıncılık. Ankara 2001;2.basım:21-50.

Mense S. Nociception from skeletal muscle in relation to clinical muscle pain. Pain 1993; 54: 241 89.

Dray A, Perkins MN. Bradykinin and inflammatory pain, trends. Physiol Rev. 1994;74:95-138.

Schouenborg J, Sjolund B. First-order nociceptive synapses in rat are blocked by an amino acid antagonist. Brain Res 1986;376:394-8.

Sorkin L, McAdoo DJ. Amino acids and serotonin are released into the lumbar spinal cord of the anesthesized cat following intradermal capsaicin injections. Brain Res 1993;607:89-98.

Wang SM, Kain ZN. Auricular acupuncture: a potential treatment for anxiety. Anesth Analg. 2001 Feb;92(2):548-53.

Cervero F. Sensory innervation of the viscera: Peripherals basis of visceral pain. Physiol Rev. 1994;74: 95-138.

Cho SY, Kim M, Sun JJ, Jahng GH, Kim HJ, Park SU, Jung WS, Ko CN, Park JM. A comparison of brain activity between healthy subjects and stroke patients on fMRI by acupuncture stimulation. Chin J Integr Med. 2013 Apr; 19(4):269-76. 


\section{$\overline{\text { International Indexed \& Refereed }}$

Wang SM, Kain ZN. Auricular acupuncture: a potential treatment for anxiety. Anesth Analg. 2001 Feb;92(2):548-53.

Uvnas-Moberg K. Oxytocin may mediate the benefits of positive social interaction and emotions. Psychoneuroendocrinol 1998; 23: 819-35.

Ullet GA, Han S, Han JS. Electroacupuncture: Mechanism and clinical application. Biol Psychiatry 1998; 44:129-38.

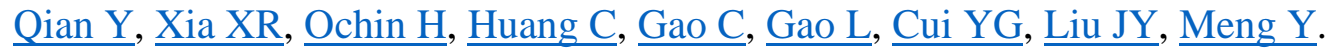

Therapeutic effect of acupuncture on the outcomes of in vitro fertilization: a systematic review and meta-analysis. Arch Gynecol Obstet. 2017 Mar;295(3):543-558. doi: 10.1007/s00404-0164255-y. Epub 2016 Dec 19

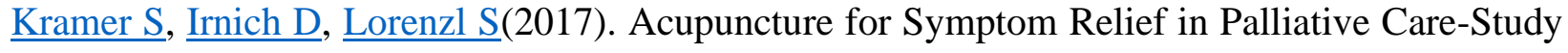
Protocol and SJ Acupunct Meridian Stud. Aug;10(4):294-302.emistandardized Treatment Schemes.

Bao MH, Zhang YW, Lou XY, Cheng Y, Zhou HH. Protective effects of let-7a and let-7b on oxidized low-density lipoprotein induced endothelial cell injuries. PLoS One. 2014;239:e106540. DOI: 10.1371/journal.pone.0106540 